\title{
Predictors of Prenatal Empowerment Among Iranian Pregnant Women
}

\author{
Narjes Sadat Borghei ${ }^{1,2}$, Ali Taghipour ${ }^{3}$, Robab Latifnejad Roudsari ${ }^{4}$, Afsaneh Keramat ${ }^{5}$, Hadi Jabbari Noghabi ${ }^{6}$
}

${ }^{1}$ Ph.D. in Reproductive Health, Assistant Professor, Department of Midwifery, School of Nursing and Midwifery, Counseling and Reproductive Health Research Center, Golestan University of Medical Sciences, Gorgan, Iran

${ }^{2}$ Graduate, Department of Midwifery, School of Nursing and Midwifery, Mashhad University of Medical Sciences, Mashhad, Iran

${ }^{3}$ MD, Ph.D. in Social Epidemiology, Associate Professor, Department of Biostatistics and Epidemiology, Management and Social Determinants of Health Research Center, School of Health, Mashhad University of Medical Sciences, Mashhad, Iran

${ }^{4}$ Ph.D. in Reproductive Health, Associate Professor, Evidence-Based Care Research Centre, Department of Midwifery, School of Nursing and Midwifery, Mashhad University of Medical Sciences, Mashhad, Iran

${ }^{5}$ Ph.D. in Family Health, Associate Professor, Department of Midwifery, Faculty of Nursing and Midwifery, Shahroud University of Medical Sciences, Shahroud, Iran

${ }^{6}$ Ph.D. of Statistics, Associate Professor, Department of Statistics, Faculty of Mathematical Sciences, Ferdowsi University of Mashhad, Mashhad, Iran

\section{Type of article: Original}

\begin{abstract}
Introduction: Considering that empowering expectant mothers is an important issue to maintain a healthy pregnancy, this study was conducted to evaluate the predictors of empowerment among Iranian pregnant women. Methods: This cross sectional study was conducted in Golestan, North of Iran in 2015. A total number of 161 pregnant women were selected through random cluster sampling from urban health centers, using PASS software. The socio-political, educational, and mental-financial predictors of empowerment were measured using a selfstructured questionnaire during pregnancy and was analyzed by a linear regression model using SPSS version 16. Results: The findings of linear regression showed that educational dimension of empowerment had the highest coefficient in the regression model, on total empowerment (ßeta standardized coefficient $[\beta]=0.696$ with $\mathrm{DW}=1.830$ and means error $=0$ ). The total empowerment score of pregnant women was controlled by individual factors such as the age of marriage ( $\beta-0.228)$, employment $(\beta-0.210)$, and educational factors such as participation in prenatal education classes ( $\beta-0.246)$, and moral issues such as sense of spiritual support $(\beta-0.217)$.

Conclusion: By recognizing and observing predictors of empowerment during pregnancy, health care providers can increase women's power over their pregnancy. Educational predictors of empowerment were the most important factors to empower women during pregnancy. The objective of childbirth education classes, therefore, should shift from simply giving information to women, towards giving them appropriate knowledge in order to provide them with empowerment during pregnancy.
\end{abstract}

Keywords: Empowerment, Pregnancy, Health

\section{Introduction}

Empowerment appears to mainly affect the use of prenatal care services and with the promotion of empowerment during pregnancy, we can improve mothers' reproductive health (1). It is necessary for all women to make proactive decisions about their health and pregnancy in order to demonstrate their many capabilities and control their fate (2). Empowerment during pregnancy helps women attain the necessary skills to correctly approach problems that may

\section{Corresponding author:}

Associate Professor Dr. Ali Taghipour, Department of Biostatistics and Epidemiology, Management and Social Determinants of Health Research Center, School of Health, Mashhad University of Medical Sciences, Mashhad, Iran Tel: +985118515118, Email: taghipoura@mums.ac.ir

Received: May 01, 2016, Accepted: July 12, 2016, Published: September 2016

iThenticate screening: July 12, 2016, English editing: August 02, 2016, Quality control: September 04, 2016

(C) 2016 The Authors. This is an open access article under the terms of the Creative Commons Attribution-NonCommercialNoDerivs License, which permits use and distribution in any medium, provided the original work is properly cited, the use is non-commercial and no modifications or adaptations are made. 
emerge. These skills would also be useful in future situations, particularly during the maternal period (3). The International Conference on Population and Development (ICPD) in 1994 emphasized the maternal empowerment as an essential component for reaching gestational and population health (4). One of the most critical responsibilities of governments is removing women's empowerment barriers, and improving gestational health by any approach possible. Also, the ICPD in Beijing (1995) considered the empowerment of women as a necessary component for reaching sustainable development in all aspects of life, and improving gestational health (4, 5).Some research demonstrates that mothers with higher skills and competency pass their pregnancy period with fewer problems and display a higher performance when taking care of and raising their children after labor (6-8). Such greater empowerment, consequently results in the establishment of a stronger family (9). Not many studies regarding empowerment during pregnancy are conducted in Iran. According to a study, there was relationship between female empowerment and gestational behavior, and researchers emphasized that increasing women's potential and capabilities through advancing their knowledge level, improving their training levels, and emphasizing their empowerment are at the forefront of national issues (6). In another study that examined the effects of an empowerment-based educational package on prenatal empowerment, results showed that educational programs can increase pregnant mothers' empowerment (7). In addition, researchers in two studies on Iranian women's' empowerment concluded that social factors and training are necessary tools for empowerment, and paying attention to women's empowerment is important $(10,11)$. It can be accepted that these studies were not sufficient and the predictor of prenatal empowerment in Iran was unknown. But in some African countries, research has been conducted on prenatal empowerment $(1,12,13)$. The cultural context of these countries differs from Iran, and empowerment depends on the context of the respective countries (14). Maternal mortality ratio (MMR) in certain developing countries can be reduced via the promotion of women's empowerment during pregnancy $(9,15)$. Lack of women's empowerment is the main cause of maternal mortality and without empowerment, the goal of reducing the rate of maternal mortality cannot be reached (16). The annual reduction rate of MMR in the Islamic Republic of Iran in 1990-2000 was 8.9\% in comparison with 3\% between $2005-2015$, showed that the reduction in MMR remained near steady in the following years (17). It has been shown that there is a relationship between socioeconomic inequalities and MMR in Iran (18). Particularly in certain ethnic groups, such as the Turkman in Golestan province, the MMR is 2.2 times higher than Fars ethnicity group (19). In This situation, when a husband's knowledge is inferior, and the mother's capabilities of making decisions for their health care are hindered, it causes an increase in maternal mortality (20). In order to solve this problem, we need to evaluate the predictors of prenatal empowerment to empower pregnant women by health care providers and encourage them to make their own decisions regarding their health during pregnancy (15). This cross-sectional study was conducted to evaluate pregnancy empowerment predictors while considering the importance of maternal empowerment in the context of Iran.

\section{Material and Methods}

\subsection{Research design, setting and data collection}

This cross-sectional study was conducted in Golestan province, northwestern Iran, an area which has divers ethnicity. Random cluster sampling was utilized in this study. In order to perform this, first an exact number of urban medical centers and clinics were listed; then Golestan were divided into five different regions (including central, eastern, western, southern and northern regions) and two health centers from each region (totally 10 centers) were selected randomly. To determine the sample size, pilot sampling was conducted and data from 20 samples was obtained. This data were entered into the SPSS software, and then using PASS software, and correlation assessment between empowerment dimensions in Kameda pregnancy empowerment and the Spritzer psychological empowerment in the first sample, and considering $\alpha=0.05, \beta=0.2$ and 0.80 power, finally a minimum sample size of 141 samples was estimated. With this information, 180nulliparous pregnant mothers, or mothers who had delivered during the last two months were selected. After the exclusion of 19 participants, either because of lack of interest to participation, illiteracy or being foreign nationals, 161 mothers personally completed questionnaires during three months in spring 2014. Questionnaires were then checked by a midwife, and returned to the mothers if any questions remained unanswered, until completion. Sense of spiritual support was quantified, based on four questions on the subject of spirituality: Trust in God in all things, acceptance of the judgment of God, appealing to Imams to fulfill wishes, and belief in God through hardship. (Each question scored from 1-4). Ownership score was measured by the quantity of the mothers' property and belongings, for example house, car and home were each rated as $\mathrm{n}=0$ and $\mathrm{y}=1$.

\subsection{Empowerment Scale}

An Iranian questionnaire, was used in this survey, for measurement of socio-political, educational, and mentalfinancial predictors of empowerment in pregnant mothers. This 32-item questionnaire's validity and reliability, were investigated by authors of this study in 2015. The score of this scale was between 32 and 128, and the average 
http://www.ephysician.ir

content validity index (S-CVI/Ave) of this scale was estimated as $91.34 \%$. Construct validity of scale were evaluated by exploratory factor analysis. The internal consistency of the scale was determined as $93.3 \%$ using the $\alpha$ Cronbach coefficient, which was higher than $70 \%$ for all sub-scales (21).

\subsection{Statistical analysis}

To study empowerment predictors in pregnancy, the linear regression method was applied. To perform a linear regression analysis, the following requirements are considered: The mean error value must be zero and the errors should have a constant variance. The errors must be independent and Durbin-Watson (DW) statistics must be in the range of 1.5-2.5, and the errors must have normal distribution. Independent variables are linearly non-correlated, so that collinearity tests must be performed on them in a way that $\mathrm{VIF}<10$ and Tolerance $>0.1$ (22). To investigate three groups of empowerment predictors, first, each group of predictors should be separately computed and then the overall empowerment predictors are to be analyzed.

\subsection{Ethical considerations}

The permission for this study was issued after the study was approved by research committee and regional committee of ethics on 25.01.2014. The study protocol meets the ethical guidelines of the 1975 Declaration of Helsinki and all ethical considerations such as voluntarily participation with complete awareness, and consenting for the study were practiced. Mothers were reassured about the privacy of their data and they were informed that only the researcher had access to collected data, and personal information (name and surname), were entered as code numbers into software, and all data were securely protected. A consent form were given to them before the questionnaire were completed.

\section{Results}

\subsection{Demographic characteristic of participant}

Of the pregnant mothers, 92.5\% were "gravid 1" and most of families (87\%) lived independently with their husbands (Table 1). The average empowerment for three dimensions is presented in Table 2. Before importing variables in the regression model, the requirements of linear regression was considered (Tables 3, 4), and the correlation of all variables should be assessed, so only variables that correlate with dependent variable are imported to the regression model. Thus, the correlation matrix of the dependent and independent variables is studied initially. In this paper, the independent variables are correlated with the dependent variable mentioned. The Durbin-Watson statistics and mean error value were calculated, where these values were suitable. Subsequently, the linear regression model was performed.

Table 1. Demographic characteristics of the participants

\begin{tabular}{|c|c|c|}
\hline \multicolumn{2}{|l|}{ Variables } & Statistics \\
\hline \multicolumn{2}{|c|}{ Age (year); Mean (SD) } & $25.08(4.79)$ \\
\hline \multicolumn{2}{|c|}{ Marriage age (year); Mean (SD) } & $22.13(4.46)$ \\
\hline \multicolumn{2}{|c|}{ Marital life length; Mean (SD) } & $2.98(1.76)$ \\
\hline \multicolumn{2}{|c|}{ Number of family members; Mean (SD) } & $2.28(0.86)$ \\
\hline \multicolumn{2}{|c|}{ Gravid; Mean (SD) } & $1.11(0.43)$ \\
\hline \multicolumn{2}{|c|}{ Sense of spiritual support score; Mean (SD) } & $14.11(1.82)$ \\
\hline \multirow[t]{3}{*}{ Education; n (\%) } & High Literacy & $63(39.1)$ \\
\hline & Intermediate & $62(38.5)$ \\
\hline & Low Literacy & $36(22.3)$ \\
\hline \multirow[t]{2}{*}{ Job } & Housewife & $129(80.1)$ \\
\hline & Employee & $32(19.9)$ \\
\hline \multirow[t]{2}{*}{ Living status } & Home Owner & $76(47.2)$ \\
\hline & Live in rental home & $85(52.8)$ \\
\hline
\end{tabular}

Table 2. The average of three dimensions of empowerment

\begin{tabular}{|l|l|l|l|l|}
\hline Dimension of empowerment & Std. Deviation & Mean & Maximum & Minimum \\
\hline Socio-political & 9.661 & 22.229 & 34 & 13 \\
\hline Autonomical & 5.080 & 23.975 & 36 & 9 \\
\hline Educational & 3.816 & 41.310 & 56 & 14 \\
\hline Total Empowerment & 14.532 & 90.764 & 130 & 44 \\
\hline
\end{tabular}


Table 3. Result of linear regression model for predictive Factors of empowerment

\begin{tabular}{|c|c|c|c|c|c|c|c|c|c|}
\hline \multicolumn{2}{|c|}{ Empowerment predictors } & \multicolumn{2}{|c|}{$\begin{array}{l}\text { Unstandardized } \\
\text { Coefficients }\end{array}$} & $\begin{array}{l}\text { Standardized } \\
\text { Coefficients } \\
\text { Beta } \\
\end{array}$ & $\begin{array}{l}\mathrm{p}- \\
\text { value }\end{array}$ & Tolerance & VIF & DW & \multirow[t]{2}{*}{$\mathrm{R}^{2}$} \\
\hline \multirow{3}{*}{$\begin{array}{l}\text { Educational } \\
\text { Dimension }\end{array}$} & Mother age & 0.023 & 0.011 & & 0.035 & 0.954 & 1.049 & \multirow{3}{*}{1.985} & \\
\hline & $\begin{array}{l}\text { Sense of } \\
\text { Spiritual } \\
\text { Support }\end{array}$ & 0.347 & 0.109 & 0.229 & 0.002 & 0.995 & 1.005 & & \multirow{2}{*}{0.648} \\
\hline & $\begin{array}{l}\text { Attendance in } \\
\text { prenatal } \\
\text { classes }\end{array}$ & 0.479 & 0.107 & 0.329 & $0.000 *$ & 0.958 & 1.043 & & \\
\hline \multirow[t]{4}{*}{$\begin{array}{l}\text { Autonomy } \\
\text { Dimension }\end{array}$} & $\begin{array}{l}\text { Employment } \\
\text { of mothers }\end{array}$ & 0.305 & 0.109 & 0.216 & 0.006 & 0.782 & 1.279 & \multirow[t]{4}{*}{1.832} & \multirow[t]{4}{*}{0.527} \\
\hline & Marriage age & 0.040 & 0.009 & 0.314 & 0.000 & 0.929 & 1.076 & & \\
\hline & $\begin{array}{l}\text { Duration of } \\
\text { Marriage }\end{array}$ & 0.067 & 0.024 & 0.210 & 0.005 & 0.848 & 1.179 & & \\
\hline & $\begin{array}{l}\text { living in } \\
\text { private home }\end{array}$ & 0.178 & 0.079 & 0.158 & 0.026 & 0.945 & 1.058 & & \\
\hline \multirow[t]{3}{*}{$\begin{array}{l}\text { Socio-political } \\
\text { Dimension }\end{array}$} & $\begin{array}{l}\text { Employment } \\
\text { of mothers }\end{array}$ & 0.147 & 0.083 & 0.139 & 0.049 & 0.959 & 1.043 & \multirow[t]{3}{*}{1.839} & \multirow[t]{3}{*}{0.585} \\
\hline & $\begin{array}{l}\text { Sense of } \\
\text { spiritual } \\
\text { support }\end{array}$ & 0.151 & 0.072 & 0.162 & 0.037 & 0.986 & 1.014 & & \\
\hline & Marriage age & 0.016 & 0.007 & 0.169 & 0.033 & 0.951 & 1.051 & & \\
\hline \multirow{4}{*}{$\begin{array}{l}\text { Total } \\
\text { empowerment }\end{array}$} & Marriage age & 0.248 & 0.078 & 0.228 & 0.002 & 0.942 & 1.061 & \multirow[t]{4}{*}{1.57} & \multirow[t]{4}{*}{0.506} \\
\hline & $\begin{array}{l}\text { Employment } \\
\text { of mothers }\end{array}$ & 2.537 & 0.878 & 0.210 & 0.004 & 0.913 & 1.096 & & \\
\hline & $\begin{array}{l}\text { Sense of } \\
\text { Spiritual } \\
\text { Support }\end{array}$ & 2.307 & 0.741 & 0.217 & 0.002 & 0.987 & 1.013 & & \\
\hline & $\begin{array}{l}\text { Attendance in } \\
\text { prenatal } \\
\text { classes }\end{array}$ & 2.515 & 0.734 & 0.246 & 0.001 & 0.935 & 1.069 & & \\
\hline \multirow[t]{3}{*}{$\begin{array}{l}\text { Total } \\
\text { empowerment }\end{array}$} & $\begin{array}{l}\text { Socio- } \\
\text { Economic } \\
\text { Dimension }\end{array}$ & 2.987 & 0.037 & 0.262 & 0.000 & 0.798 & 2.987 & \multirow[t]{3}{*}{1.830} & \multirow[t]{3}{*}{0.699} \\
\hline & $\begin{array}{l}\text { Autonomy } \\
\text { Dimension }\end{array}$ & 3.022 & 0.027 & 0.352 & 0.000 & 0.818 & 3.022 & & \\
\hline & $\begin{array}{l}\text { Educational } \\
\text { Dimension }\end{array}$ & 4.886 & 0.022 & 0.696 & 0.000 & 0.875 & 4.886 & & \\
\hline
\end{tabular}

Table 4. Result of normality of Unstandardized Residual of dimension of empowerment

\begin{tabular}{|l|l|l|l|l|l|l|}
\hline Unstandardized Residual of dimension of empowerment & \multicolumn{3}{|l|}{ Shapiro-Wilk } & \multicolumn{3}{l|}{ Kolmogorov-Smirnova } \\
\cline { 2 - 7 } & Statistic & Df & Sig & Sig & Df & Statistic \\
\hline Socio-political & 0.989 & 161 & 0.246 & 0.040 & 161 & 0.200 \\
\hline Autonomical & 0.984 & 161 & 0.057 & 0.063 & 161 & 0.200 \\
\hline Educational & 0.986 & 161 & 0.219 & 0.059 & 161 & 0.200 \\
\hline Total Empowerment & 0.988 & 161 & 0.262 & 048 & 161 & 0.200 \\
\hline
\end{tabular}

\subsection{Educational Dimension of Empowerment}

Initially, variables including mother's age, marital age, employment of mothers, participation in prenatal education classes, marital satisfaction score, and sense of spiritual support score, as correlated factors in educational empowerment, are imported to the linear regression model. The results show that the "participation in pregnancy classes", "spiritual support" and "mother's age", are predictors of educational empowerment indexes (Table 3). Mothers with higher age, who participated in prenatal education and received better emotional support, indicate higher educational empowerment. In other words, the educational empowerment formula of the pregnant mothers 
with Constant of 0.998 is as follows: Educational Dimension of Empowerment $=0.998+0.479$ (Participation in prenatal education classes) +0.347 (Sense of spiritual support) +0.023 (Mother's age) .

\subsection{Autonomy (Mental-financial in dependency) Dimension of Empowerment}

variables including mother's age, marital age, marital life length, Fars ethnicity, mother and father literacy level, living status, ownership score, participation in prenatal educational classes, employment of mother and ownership of a property by credit arrangement, are imported to the linear regression model as correlated factors in autonomy dimension of empowerment. The results show that "marital life length", "employment of mothers", and "living in her own home" are as a predictors of mental-financial independent empowerment indexes (Table 3). Mothers of senior age and longer marital period, and those who are living in their own private home indicate higher empowerment in independency and autonomy. In other words, the Autonomy dimension of empowerment formula in pregnant mothers with Constant of 1.426 is as follows: Autonomy Dimension of Empowerment $=1.426+$ 0.305 (Employment of mother) +0.178 (Living in own home) +0.067 (Marital life length) +0.040 (marriage age) .

\subsection{Socio-Political predictors of Empowerment}

The linear regression model was used to evaluate socio-political variables including: mother's age, marriage age, employment of mother, mother's level of literacy, and sense of spiritual support .The results show that the "marriage age", "sense of spiritual support" and "employment of mother" are predictors in socio-political empowerment (Table 3). The study indicates that mothers with higher marriage age and high sense of spiritual support who are employed, have higher socio-political empowerment. In other words, the socio-political dimension of empowerment formula in pregnant mothers with Constant of 2.122 is as follows: Socio-political Dimension of Empowerment=1.554 + 0.151 (Sense of spiritual support) +0.147 (Employment of mother) +0.016 (Mother marriage age) .

\subsection{Total Empowerment score}

Maternal age, the age of marriage, the length of marital life, employment of mother, mother and father's literacy level, spiritual support and participation in prenatal educational classes were variables that correlated with the total empowerment score. To evaluate the total empowerment in pregnant women the data was imported to the linear regression model. The results show that the "participation in pregnancy classes", "spiritual support", "marriage age" and "employment of mother" are important predictors of total empowerment indexes; and mothers with higher marriage age and those who were employed and participated in prenatal educational classes and have high spiritual support, indicate higher total empowerment (Table 3). In other words, the total empowerment formula in pregnant mothers with Constant of 15.253 is as follows: Total Empowerment $=15.253+2.537$ (Employment of mother) + 2.515 (Participation in prenatal education classes) +2.307 (Sense of Spiritual support) +0.248 (marriage age) .

\subsection{Total Empowerment}

Variables including the level of mother's education, autonomy and socio-political empowerment were imported to the linear regression model. The results show that "educational empowerment" has the greatest impact on total empowerment (Table3); therefore, total empowerment formula in pregnant mothers with Constant of 0.409 is as follows: Total Empowerment $=0.409+4.886$ (Educational dimension) +3.022 (Autonomy empowerment) + 2.987(Socio-political empowerment).

\section{Discussion}

As the result of this study shows, the level of empowerment in women during pregnancy will be predictable, based on three main factors: a) The individual characteristic of the pregnant woman, such as, mother's age, marriage age, the length of marriage; b) the socio-economic status of the mother, for example, mother's employment, living in her own home; and c) the educational factors, including, participation in prenatal education classes and having spiritual support. The employment, learning professional skills and financial stability are the common elements that most researchers agreed on (10). In fact, employment and learning professional skills leads to womens' financial stability. Studies showed that having higher education helps women to reach a better financial and legal stability that effect on their level of health, and a direct effect in their empowerment (23). Renkert (2001) believed that to progressively increase the level of education would cause a higher independency in decision making and individual empowerment (8). In this study, there is a high correlation between education and employment, and these two factors together should not be inserted in regression model with high correlation (22). So, due to the fact that higher education increases the chance of employment of women, we include employment in our linear regression model. The finding showed that employment plays the predicator role in all empowerment dimensions except education. This study shows that with the increase in mother employment, the marriage age, socio-political, autonomy and total 
empowerment increase too. Surely, employment and learning professional skills have more significant effect on economical dimensions in the empowerment of women. In fact, women's employment helps their social, political, and psychological dimensions of their empowerment (11). Financial resources such as, having a job and monthly income are the most important elements of women's empowerment $(10,11)$.As Table 3 shows, living in their own home, and ownership, predict the autonomy factor of empowerment. If we consider home ownership as a predictor for a better financial status, women who live in their own home have higher empowerment. Ahmad (2010) believed that in developing countries, to improve mothers' health, the economic, social and educational situation of mothers must improve (15). There were relations between the educational-economical situation and decision making power for seeking health care $(15,24)$. Another study performed in Iran, considered the socio-economical factors as the determinants of empowerment (6). A research has been conducted in Ethiopia regarding women's autonomy dimension of empowerment. This study considered mother employment as the main factor in mother and child health, and as the predicator of mother's mental-financial autonomy empowerment (13). Ahmad (2010) believes that the women with more empowerment have more autonomy and they are healthier (15). Decision making power and control over her own life are the elements of autonomic empowerment, which are affected directly from mothers employment $(15,25)$. In many studies, employment, economical status and wealth and ownership of properties have been elements of mothers' empowerment (26-28). Mothers' age and wealth have been the main elements that effect on the presence of their spouse at prenatal care visits. Ahmad found out in his studies that there was a positive and strong relation between key elements of social economical situation and health of mothers in 31 developing countries, which includes $20 \%$ of world population (15). In this study we observed that "age of marriage" predicts socio-political, autonomy and total empowerment. A mothers 'age predicts educational empowerment and the length of marital life predicts autonomy empowerment. There was relation between economical situation, level of education and mother empowerment which was controlled by mother's age (15). In a study conducted in Iran, mother's age, marriage age, age at first pregnancy, and the educational level, are the main affecting factors on mother's empowerment (6). In fact it seems that age has a fundamental effect on mother's empowerment (15). Other elements such employment, economical situation, spiritual and educational status are the following effective factors in women's empowerment. In addition, education is the most important empowerment tool. As it improves women's knowledge, skills, and self-confidence, which consequently result in female participation in the developmental, process (4). In this study, mothers' participation in prenatal educational classes has been considered as a predictor of educational and total empowerment. Since educational empowerment has the highest coefficient in regression model and on total empowerment, its plausible to promote educational and total empowerment with training and educational programs that emphasize on empowering mothers. The effect of training programs on mother empowerment has been observed in Jahdi's study, which showed that training is motivational and the actuating force in empowering women during pregnancy. And it is the first major guide line in planning and engaging programs to empower women. Pregnancy training empowers women to understand and adapt to physical and behavioral changes during pregnancy. Also, group training under supervision of health care provider, offers mothers the opportunity to listen and learn from others' experiences and knowledge during class discussions. Group training also promotes bonding and friendship among expectant mothers, and it increase social and self-care empowerment among them (7). In a study on relation between empowerment and pregnant behavior, it suggested that the training is a determinant element of empowerment. And it considered that countries need to pay a special attention to increase women's knowledge and training, in order to empower women and to increase their capability and power over their pregnancy (6). A study on 195 women that evaluated the effect of monitoring women empowerment by health care providers, emphasized on the importance of education during pregnancy and the role of health care providers in educating women during pregnancy (29). Public training is confirmed as an effective element in empowerment in other studies too $(1,10)$. As it mentioned before, the finding of this study confirmed the effect of spiritual support in women empowerment during pregnancy. There are many studies about relations between spiritual support and empowerment. Kidwai (2013) believed that there is a relation between spirituality of a person and the level of distress she may suffer; and the course of this relation (positive or negative) related to a person's cultural and personal background (30). In fact spiritual belief and belief in God gives people a positive or negative perspective toward dealing with distress. People who have positive attitudes and have believed in God have more mental and emotional comfort (31-33). Believing in as high a power as God, empowers the believers and increases their coping skills $(34,35)$. In Iran, due to Islamic religious believes people who find themselves under the grace of God, have more comfort and have less tension and stress.

\section{Limitations of the study}

In this study, three predictors of mother's empowerment, including socio- economic, autonomy and educational status have been surveyed by a scale which has been designed particularly for nulliparous Iranian pregnant women. 
But to plan a comprehensive educational program that covers all aspects of empowerment during pregnancy for all groups of pregnant women, it is important to survey multiparous pregnant women, as well as high risk pregnant women using a larger sample size.

\section{Conclusions}

It can be concluded from this study that employment and the age of marriage are the main predicators of empowerment. Since employed women tend to marry in more mature ages and with a better socio-economic situation, they have more empowerment during pregnancy. According to the findings of this study, education has the greatest effect and highest coefficient on total empowerment in mothers. So, it is necessary to have an accurate program which emphasize in training during pregnancy. In this program we should be able to recognize mothers in need, and provide a special training program for them to increase their health and empowerment during pregnancies, which guide them to a safer pregnancy and motherhood. Our study showed that mothers who find themselves under God's protection and feel spiritual support, have more empowerment. Thus, having spiritual support and participating in pregnancy classes are the two important predictors of educational empowerment and empowerment in total.

\section{Acknowledgments:}

This study is a PhD thesis in reproductive health (approved on 15.01. 2014, Research Deputy of Mashhad University of Medical Science, with Grant number of 921488). Authors appreciate the research deputy of Mashhad University of Medical Science for approval and financial support. Also we show our highest gratitude towards all midwives who work in Golestan Health Centers for their cooperation, all pregnant women for their participation in this study and my colleague Ruhangiz Mahjoub RN, MSN, PHN, PCCN for English editing.

\section{Conflict of Interest:}

There is no conflict of interest to be declared.

Authors' contributions:

All authors contributed to this project and article equally. All authors read and approved the final manuscript.

\section{References:}

1) Sipsma H, Ofori-Atta A, Canavan M, Udry C, Bradley E. Empowerment and use of antenatal care among women in Ghana: a cross-sectional study. BMC Pregnancy Childbirth. 2014; 14(1): 364 . doi: 10.1186/s12884-014-0364-4.

2) Yazdkhasti M, Simbar M, Abdi F. Empowerment and Coping Strategies in Menopause Women: A Review. Iran Red Crescent Med J Review Article. 2015; 17(3): e18944. doi: 10.5812/ircmj.18944. PMID: 26019897, PMCID: PMC4441783.

3) Dumas L. Focus groups to reveal parents' needs for prenatal education. J Perinat Educ. 2002; 11(3): 1-9. doi: 10.1624/105812402X88786. PMID: 17273303, PMCID: PMC1599796.

4) McIntosh CA, Finkle JL. The Cairo conference on population and development: A new paradigm? Population and development review. 1995; 21(2): 223-60. doi: 10.2307/2137493.

5) Moss NE. Gender equity and socioeconomic inequality: a framework for the patterning of women's health. Soc Sci Med. 2002; 54(5): 649-61. doi: 10.1016/S0277-9536(01)00115-0. PMID: 11999484.

6) Froozanfar S, Majlessi F, Rahimi Forroshani A, Pour Reza A. Assesment of the Relationship between Empowerment and Reproductive Behavior. Daneshvar Medicine. 2012; 19(99): 39-46.

7) Jahdi F, Montazeri A, Balouchi M, Behboodi Moghadam Z. The impact of group prenatal care on pregnant women empowerment. Journal of the Iranian Institute for Health Sciences Research. 2014; 13(2): 229-34.

8) Renkert S, Nutbeam D. Opportunities to improve maternal health literacy through antenatal education: an exploratory study. Health Promot Int. 2001; 16(4): 381-8. doi: 10.1093/heapro/16.4.381. PMID: 11733456.

9) Rahimi $T$. The basic strategies for improving health and reducing maternal mortality. National Congress of strategies for improving health and reducing maternal mortality. IRAN. 2014; 27-28.

10) Gholipour A, Rahimian A. Economic, Cultural, and Educational Factors Related to Empowerment of Headof-Household Women. Social Welfare Quarterly. 2011; 11(40): 29-62.

11) Shady Talab Z, Gheraee nejad A. Poverty in female-headed households. Women in Development \& Politics. 2003; 8: 49-70.

12) Jennings $L$, Na M, Cherewick M, Hindin M, Mullany B, Ahmed S. Women's empowerment and male involvement in antenatal care: analyses of Demographic and Health Surveys (DHS) in selected African countries. BMC Pregnancy Childbirth. 2014; 14: 297. doi: 10.1186/1471-2393-14-297. 
13) Nigatu D, Gebremariam A, Abera M, Setegn T, Deribe K. Factors associated with women's autonomy regarding maternal and child health care utilization in Bale Zone: a community based cross-sectional study. BMC women's health. 2014; 14(1): 79. doi:10.1186/472-6874-14-79.

14) Zimmerman MA. Psychological empowerment: issues and illustrations. Am J Community Psychol. 1995; 23(5): 581-99. doi:10.1007/BF02506983. PMID: 8851341.

15) Ahmed S, Creanga AA, Gillespie DG, Tsui AO. Economic status, education and empowerment: implications for maternal health service utilization in developing countries. PLoS One. 2010; 5(6): e11190. doi: 10.1371/journal.pone.0011190.

16) Abrejo FG, Shaikh BT, Saleem S. ICPD to MDGs: Missing links and common grounds. Reproductive Health. 2008; 5(4): 1-8. doi: 10.1186/742-4755-5-4.

17) WHO, UNICEF, UNFPA, World Bank Group, and United Nations Population Division. Maternal mortality in 1990-2015, IRAN (ISLAMIC REPUBLIC OF). Maternal Mortality Estimation Inter-Agency Group. Available from: www.who.int/gho/maternal_health/countries/irn.

18) Tajik P, Nedjat S, Afshar NE, Changizi $\bar{N}$, Yazdizadeh B, Azemikhah A, et al. Inequality in maternal mortality in Iran: an ecologic study. Int J Prev Med. 2012; 3(2): 116-21. PMID: 22347608, PMCID: PMC3278876.

19) Rahimian S. Relationship of maternal mortality by ethnicity in Golestan Province. National Congress of strategies for improving health and reducing maternal mortality. 2014; 27-8.

20) Dah Mardehei M, Hormozy F, Hagh parast $H$. The impact of socio-economic factors, especially poverty on maternal mortality and reduction of its effect National Congress of strategies for improving health and reducing maternal mortality. 2014; 27-28.

21) Borghei NS, Taghipour A, Roudsari RL, Keramat A. Development and Validation of a new tool to measure Iranian pregnant Women's empowerment. EMHJ. 2015; 21(12): 897-905.

22) Niromand H. Linear regression analysis. A Tool for Research. Iran: Arsalan. 2009.

23) Ketabi M, Yazdkhasti B, Rastaee F. Preconditions and obstacles to women's empowerment: Women of Isfahan Case Study. The Quarterly Journal of Human Sciences University of Isfahan. 2005; 19(2): 1-20.

24) Bloom SS, Wypij D, Das Gupta M. Dimensions of women's autonomy and the influence on maternal health care utilization in a north Indian city. Demography. 2001; 38(1): 67-78. doi: 10.1353/dem.2001.0001.

25) Kimiaee S. Methods Used for Empowering Head-of-Household Women. Social Welfare Quarterly. 2011; 11(40): 63-92.

26) Frankenberg E, Thomas D. Women's Health and Pregnancy Outcomes: Do Services Make a Difference? Demography. 2001; 38(2): 253-65. doi: 10.1353/dem.2001.0014. PMID: 11392911.

27) Jejeebhoy SJ. Women's autonomy in rural India: Its dimensions, determinants, and the influence of context. New York: Oxford University Press. 2000.

28) Woldemicael G. Do women with higher autonomy seek more maternal health care? Evidence from Eritrea and Ethiopia. Health Care Women Int. 2010; 31(7): 599-620. doi: 10.1080/07399331003599555. PMID: 20526926.

29) Santos I, Barroca I, Ferreira M, Pereira D. Pregnant women's empowerment during pregnancy surveillance [Research project]. Oxford, England: Oxford University. 2011.

30) Kidwai R, Mancha BE, Brown QL, Eaton WW. The effect of spirituality and religious attendance on the relationship between psychological distress and negative life events. Soc Psychiatry Psychiatr Epidemiol. 2014; 49(3): 487-97. doi: 10.1007/s00127-013-0723-x. PMID: 23732707, PMCID: PMC4157065.

31) Ano GG, Vasconcelles EB. Religious coping and psychological adjustment to stress: a meta-analysis. J Clin Psychol. 2005; 61(4): 461-80. doi: 10.1002/jclp.20049. PMID: 15503316.

32) Pargament KI, Koenig HG, Perez LM. The many methods of religious coping: development and initial validation of the RCOPE. J Clin Psychol. 2000; 56(4): 519-43. doi: 10.1002/(SICI)97. PMID: 10775045.

33) Pargament KI, Smith BW, Koenig HG, Perez L. Patterns of positive and negative religious coping with major life stressors. Journal for the Scientific Study of Religion. 1998; 37(4): 710-24. doi: $10.2307 / 1388152$.

34) Schieman S, Pudrovska T, Milkie MA. The sense of divine control and the self-concept a study of race differences in late life. Research on Aging. 2005; 27(2): 165-96. doi: 10.1177/0164027504270489.

35) Schieman S, Pudrovska T, Pearlin LI, Ellison CG. The Sense of Divine Control and Psychological Distress: Variations Across Race and Socioeconomic Status. Journal for the Scientific Study of Religion. 2006; 45(4): 529-49. doi: 10.1111/j.468-5906.2006.00326.x. 